\title{
Preoperative mental health status may not be predictive of improvements in patient-reported outcomes following an anterior cervical discectomy and fusion
}

\author{
Benjamin C. Mayo, BA, Dustin H. Massel, BS, Daniel D. Bohl, MD, MPH, Ankur S. Narain, BA, \\ Fady Y. Hijji, BS, William W. Long, BA, Krishna D. Modi, BS, Bryce A. Basques, MD, \\ Alem Yacob, MD, and Kern Singh, MD \\ Department of Orthopaedic Surgery, Rush University Medical Center, Chicago, Illinois
}

\begin{abstract}
OBJECTIVE Prior studies have correlated preoperative depression and poor mental health status with inferior patientreported outcomes following lumbar spinal procedures. However, literature regarding the effect of mental health on outcomes following cervical spinal surgery is limited. As such, the purpose of this study is to test for the association of preoperative SF-12 Mental Component Summary (MCS) scores with improvements in Neck Disability Index (NDI), SF-12 Physical Component Summary (PCS), and neck and arm pain following anterior cervical discectomy and fusion (ACDF). METHODS A prospectively maintained surgical database of patients who underwent a primary 1- or 2-level ACDF during 2014-2015 was reviewed. Patients were excluded if they did not have complete patient-reported outcome data for the preoperative or 6-week, 12-week, or 6-month postoperative visits. At baseline, preoperative SF-12 MCS score was assessed for association with preoperative NDI, neck visual analog scale (VAS) score, arm VAS score, and SF-12 PCS score. The preoperative MCS score was then tested for association with changes in NDI, neck VAS, arm VAS, and SF12 PCS scores from the preoperative visit to postoperative visits. These tests were conducted using multivariate regression controlling for baseline characteristics as well as for the preoperative score for the patient-reported outcome being assessed.
\end{abstract}

RESULTS A total of 52 patients were included in the analysis. At baseline, a higher preoperative MCS score was negatively associated with a lower preoperative NDI (coefficient: $-0.74, p<0.001)$ and preoperative arm VAS score $(-0.06$, $p=0.026)$, but not preoperative neck VAS score $(-0.03, p=0.325)$ or SF-12 PCS score $(0.04, p=0.664)$. Additionally, there was no association between preoperative MCS score and improvement in NDI, neck VAS, arm VAS, or SF-12 PCS score at any of the postoperative time points ( 6 weeks, 12 weeks, and 6 months, $p>0.05$ for each). The percentage of patients achieving a minimum clinically important difference at 6 months did not differ between the bottom and top MCS score halves ( $p>0.05$ for each).

CONCLUSIONS The results of this study suggest that better preoperative mental health status is associated with lower perceived preoperative disability but is not associated with severity of preoperative neck or arm pain. In contrast to other studies, the present study was unable to demonstrate that preoperative mental health is predictive of improvement in patient-reported outcomes at any postoperative time point following an ACDF.

https://thejns.org/doi/abs/10.3171/2016.7.SPINE16472

KEY WORDS mental health; depression; ACDF; anterior cervical discectomy and fusion; outcomes; SF-12; NDI; neck disability index; VAS; visual analog scale

$\Lambda$ NTERIOR cervical discectomy and fusion (ACDF) is a reliable treatment option for neck pain and associated radiculopathy due to degenerative disc disease. However, some subsets of patients may not report significant improvements in pain and disability. Clinical success rates have been reported to occur in as few as $40 \%$ of patients following multilevel fusion procedures. ${ }^{8,9,15}$ It has been suggested that a patient's mental health may have an effect on postoperative outcomes..$^{21,25}$ Many psychosomatic and mood disorders have been considered to contribute to worse outcomes, though depression and anxiety have received the most attention in the literature.

ABBREVIATIONS ACDF = anterior cervical discectomy and fusion; $\mathrm{CCI}=$ Charlson Comorbidity Index; $\mathrm{MCID}=$ minimum clinically important difference; MCS = Mental Component Summary; NDI = Neck Disability Index; PCS = Physical Component Summary; PRO = patient-reported outcome; VAS = visual analog scale.

SUBMITTED April 25, 2016. ACCEPTED July 15, 2016.

INCLUDE WHEN CITING Published online September 30, 2016; DOI: 10.3171/2016.7.SPINE16472. 
While numerous studies have reported a correlation between preoperative mental health and outcomes following spinal surgery, 2,10,31,32,34,39 others have failed to find an association..$^{23,33}$ Additionally, a large majority of prior literature has focused on the effect of depression on outcomes following lumbar spine surgery, while outcomes following cervical spine surgery remain relatively unstudied. $4,16,20,22,27,41$

One widely used questionnaire to assess patient health is the SF-12 Health Survey. ${ }^{17,19}$ The SF-12 can be reported as a total score, or as a Physical Component Summary (PCS) score and a Mental Component Summary (MCS) score. While the PCS evaluates a patient's physical health status, the MCS assesses emotional health and has been validated as an acceptable screening tool for depression. ${ }^{17-19,40}$ The purpose of this study is to test for association between preoperative mental health, as assessed by the SF-12 MCS, and change in patient-reported outcomes (PROs) following an ACDF.

\section{Methods \\ Patient Population}

After obtaining institutional review board approval, we reviewed a prospectively maintained surgical database of consecutive patients who underwent a primary 1- or 2-level ACDF performed by a single surgeon at a single academic institution during 2014-2015. Only cases during this time period were selected due to recent utilization of the SF-12 patient surveys at Rush University Medical Center. All patients were asked to fill out an SF-12 survey, a Neck Disability Index (NDI), and visual analog scale (VAS) pain scores for neck and arm preoperatively, as well as at the 6-week, 12-week, and 6-month postoperative visits. Only patients who completed each patient-reported outcome survey at all 4 appointments were included in the analysis.

\section{Outcome Measures}

The SF-12 is a widely used, concise survey that evaluates overall patient health. For both SF-12 subsections (MCS and PCS), a lower score indicates worse functional status. The NDI is used to evaluate self-rated disability in patients with neck pain. A higher NDI correlates with greater disability, and a lower score indicates minimal disability. VAS is a patient-reported, site-specific pain scale. For this scale, a score of 0 indicates no pain, while a score of 10 indicates maximal pain.

Preoperative MCS score as a continuous variable was tested for association with preoperative NDI, neck VAS, arm VAS, and SF-12 PCS scores. The cutoff between the top and bottom halves of preoperative MCS scores was 47.5. The change from preoperative score was calculated for NDI, neck VAS, arm VAS, and SF-12 PCS scores at 6 weeks, 12 weeks, and 6 months postoperatively. Previously, 3-month follow-up was demonstrated to be sufficient in detecting statistically significant improvements in PROs. ${ }^{35}$ As such, 6-month follow-up was deemed appropriate in this study. These changes in patient-reported outcome scores were then tested for association with preoperative MCS score (continuous). Achievement of minimum clini-
TABLE 1. Baseline characteristics of the patient population

\begin{tabular}{cc}
\hline \multicolumn{1}{c}{ Variable } & Value \\
\hline Mean age, yrs & $49.2 \pm 9.4$ \\
\hline Sex & $22(42.3)$ \\
\hline Female & $30(57.7)$ \\
\hline Male & \\
\hline Smoking status & $47(90.4)$ \\
\hline Nonsmoker & $5(9.6)$ \\
\hline Smoker & $30(57.7)$ \\
\hline No. of levels & $22(42.3)$ \\
\hline 1 & $33(63.5)$ \\
\hline 2 & $19(36.5)$ \\
\hline Body mass index, $\mathrm{kg} / \mathrm{m}^{2}$ & $1.08 \pm 1.32$ \\
\hline$<30$ (nonobese) &
\end{tabular}

cally important difference (MCID) at the 6-month postoperative visit for NDI, neck VAS, arm VAS, and SF-12 PCS scores was compared between patients in the bottom half of the preoperative MCS score and patients in the top half of the preoperative MCS score. According to previously reported MCID, values of 17.3, 2.6, 4.1, and 8.1 were used as the MCID for NDI, neck VAS, arm VAS, and SF-12 PCS scores, respectively. ${ }^{35}$

\section{Statistical Analysis}

Statistical analysis was performed using Stata/MP (version 13.1 for Mac, StataCorp LP). First, the preoperative SF-12 MCS score was tested for association with preoperative NDI, neck VAS, arm VAS, and SF-12 PCS scores using bivariate regression to characterize baseline correlations. Second, change in NDI, neck VAS, arm VAS, and SF-12 PCS scores at each postoperative time point was tested for association with preoperative SF-12 MCS score using multivariate linear regression controlling for patient age, sex, smoking status, obesity, Charlson Comorbidity Index (CCI), insurance type, and the preoperative score for the PROs being assessed. Finally, patients in the top and bottom halves of preoperative MCS score were compared using multivariate linear regression controlling for all preoperative characteristics. A p value $<0.05$ was used to determine statistical significance.

\section{Results}

A total of 81 patients underwent a primary 1- or 2-level ACDF during the time period and were eligible for the study. Of the 81 eligible patients, 52 (64.2\%) completed all surveys at each scheduled visit and were included in the analysis. Using an SF-12 MCS score cutoff of 47.5, 26 patients were placed in the "bottom half" group and 26 patients were placed in the "top half" group. Table 1 provides demographic information regarding the study population.

The associations between preoperative MCS score and preoperative PROs are illustrated in Figs. 1 and 2. Lower 


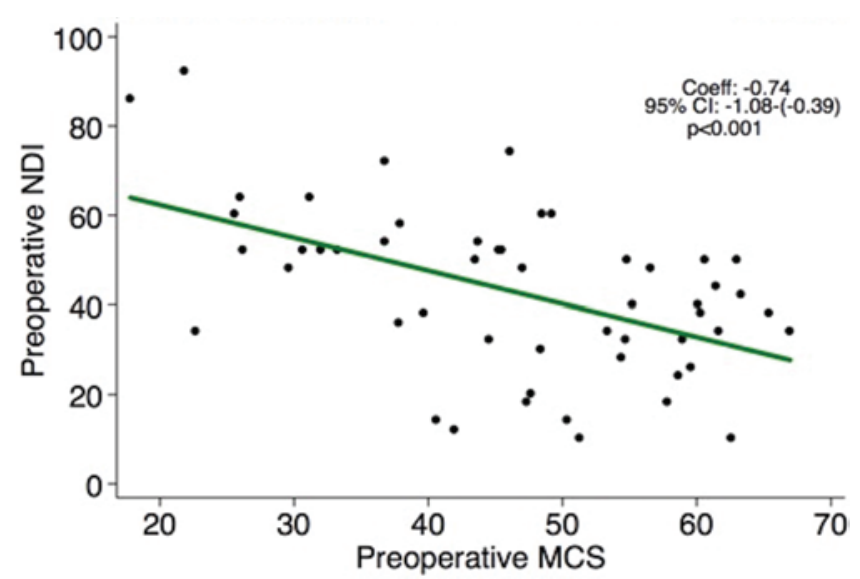

FIG. 1. Graph representing the association between preoperative mental health scores (SF-12 MCS) and preoperative NDI. Figure is available in color online only.

preoperative MCS was associated with higher preoperative NDI (coefficient $-0.74,95 \%$ CI -1.08 to -0.39 ; $\mathrm{p}<$ 0.001 [Fig. 1]) and higher preoperative arm VAS score (coefficient $-0.06,95 \%$ CI -0.11 to $-0.01 ; p=0.026$ [Fig. 2]). Preoperative MCS score was not associated with the preoperative neck VAS score (coefficient: $-0.03,95 \%$ CI -0.09 to $0.02 ; \mathrm{p}=0.325)$. Finally, preoperative MCS was not associated with preoperative SF-12 PCS (coefficient: $0.04,95 \% \mathrm{CI}-0.11$ to $0.24 ; \mathrm{p}=0.664$ ).

The associations between preoperative MCS score and changes in PROs from preoperative to postoperative visits are provided in Table 2. MCS score was not associated with change in NDI from the preoperative visit at any of the postoperative visits $(6$-week, $\mathrm{p}=0.929 ; 12$-week, $\mathrm{p}=$ 0.667 ; 6-month, $p=0.838$ ). Preoperative MCS score was not associated with change in neck VAS score from the preoperative visit at any postoperative visit (6-week, $\mathrm{p}=$ 0.586 ; 12 -week, $\mathrm{p}=0.468$; 6-month, $\mathrm{p}=0.742$ ). Similarly, preoperative MCS score was not associated with change in arm VAS score from the preoperative visit at any postoperative visit (6-week, $\mathrm{p}=0.125 ; 12$-week, $\mathrm{p}=0.635$; 6 -month, $p=0.297$ ). Finally, preoperative MCS score was not associated with change in SF-12 PCS score from the preoperative visit at any postoperative visit (6-week, $\mathrm{p}=$ 0.217 ; 12 -week, $\mathrm{p}=0.368$; 6 -month, $\mathrm{p}=0.538$ ).

Information on the achievement of MCID for each of the PROs is provided in Tables 3 and 4. There were no differences between the upper and lower halves of preoperative MCS scores for percentage of patients achieving MCID for NDI $(42.3 \%$ vs $53.9 \%, \mathrm{p}=0.788)$, neck VAS $(57.7 \%$ vs $50.0 \%, \mathrm{p}=0.519)$, arm VAS $(38.5 \%$ vs $38.5 \%, \mathrm{p}$ $=1.00)$, or SF-12 PCS $(57.7 \%$ vs $65.4 \%, \mathrm{p}=0.489)$ score. There were also no significant differences in mean preoperative MCS score between those patients who achieved MCID and those who did not for NDI $(\mathrm{p}=0.730)$, neck VAS ( $\mathrm{p}=0.883)$, arm VAS ( $\mathrm{p}=0.284)$, and SF-12 PCS ( $\mathrm{p}$ $=0.503)$ scores.

\section{Discussion}

Several risk factors have been theorized to affect PROs following spinal surgery. While some of these risk fac-

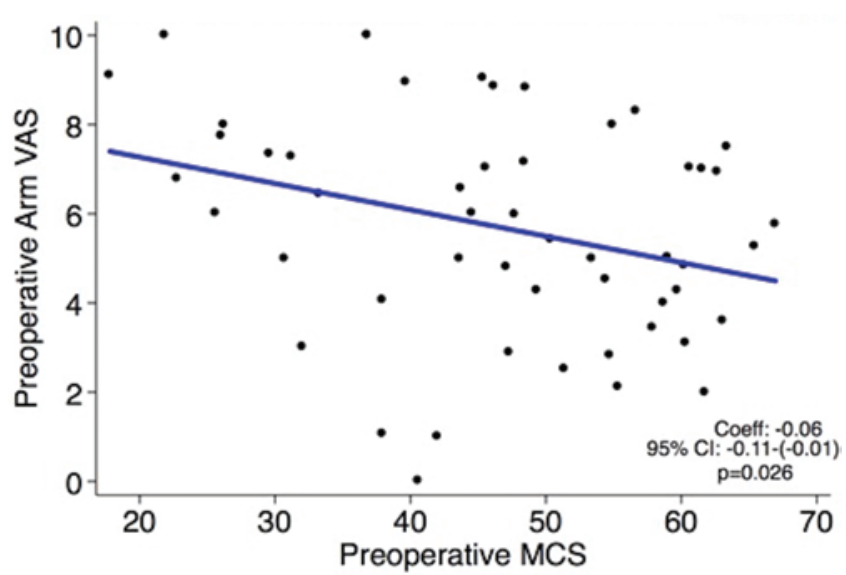

FIG. 2. Graph representing the association between preoperative mental health scores (SF-12 MCS) and preoperative arm VAS. Figure is available in color online only.

tors such as patient age and sex are not modifiable, certain medical comorbidities can be adequately treated prior to surgery. Recently, there has been an increasing focus on preoperative depression and other mental health symptoms as they have demonstrated the potential to impair the degree of improvement in PROs following spinal surgery. ${ }^{34,37}$ However, a majority of prior literature has evaluated the effect of depression on outcomes of lumbar spinal surgery, while cervical spine literature remains sparse. In this context, the purpose of this study was to evaluate whether preoperative mental health was predictive of change in outcomes in patients undergoing ACDF.

The results of this study suggest that the preoperative SF-12 MCS score is not predictive of changes in disability or pain from pre- to postoperative visits. Consistent with these results, the patients with the lowest preoperative MCS scores achieved MCID in NDI, neck VAS, arm VAS, and SF-12 PCS scores at similar rates to the patients with the highest preoperative MCS score. This suggests that surgeons should not necessarily assume that a patient with poor preoperative mental health status is likely to experience worse outcomes than a patient with no psychosomatic symptoms.

To our knowledge, no studies have reported the lack of an association between preoperative mental health status and worse outcomes following cervical spine surgery. However, few studies have examined this relationship for cervical fusion, relative to the lumbar spine literature. The results of the present study are similar to those reported by $\mathrm{Ng}$ et al. in a study of 100 patients with spinal stenosis who underwent posterior lumbar decompression; neither preoperative anxiety nor depression demonstrated an association with postoperative PRO measures. ${ }^{33}$ In a similar study examining depression and multiple other psychosomatic symptoms, Herron et al. concluded that postoperative outcomes following lumbar spine surgery were not predicted by any preoperative psychological condition. ${ }^{21}$ Similarly, Katz et al. demonstrated no association between preoperative depression and postoperative satisfaction or improvement in PROs following lumbar spine decompression with or without fusion. ${ }^{23,24}$ Lastly, depression was not found to be associated with postoperative pain or disability, despite 
TABLE 2. Preoperative MCS score association with patient-reported outcome measures

\begin{tabular}{|c|c|c|c|c|c|}
\hline Variable & Mean \pm SD & Change \pm SD & Coefficient \pm SE & $95 \% \mathrm{Cl}$ & p Value* \\
\hline \multicolumn{6}{|l|}{ NDI } \\
\hline Preop & $42.8 \pm 18.5$ & & & & \\
\hline 6-wk & $35.8 \pm 19.1$ & $-7.0 \pm 17.6$ & $0.02 \pm 0.20$ & -0.40 to 0.43 & 0.929 \\
\hline 12-wk & $30.2 \pm 21.6$ & $-12.6 \pm 17.5$ & $-0.09 \pm 0.21$ & -0.34 to 0.52 & 0.667 \\
\hline 6-mo & $26.4 \pm 22.4$ & $-16.4 \pm 20.1$ & $0.05 \pm 0.23$ & -0.43 to 0.53 & 0.838 \\
\hline \multicolumn{6}{|l|}{ VAS neck } \\
\hline Preop & $6.0 \pm 2.6$ & & & & \\
\hline 6-wk & $3.5 \pm 2.4$ & $-2.5 \pm 2.6$ & $-0.01 \pm 0.03$ & -0.07 to 0.04 & 0.586 \\
\hline 12-wk & $3.3 \pm 2.7$ & $-2.7 \pm 2.8$ & $-0.02 \pm 0.02$ & -0.07 to 0.03 & 0.468 \\
\hline 6-mo & $3.0 \pm 2.8$ & $-3.0 \pm 3.2$ & $0.01 \pm 0.03$ & -0.05 to 0.07 & 0.742 \\
\hline \multicolumn{6}{|l|}{ VAS arm } \\
\hline Preop & $5.7 \pm 2.5$ & & & & \\
\hline 6-wk & $2.4 \pm 2.2$ & $-3.3 \pm 2.8$ & $-0.04 \pm 0.02$ & -0.08 to 0.01 & 0.125 \\
\hline $12-w k$ & $2.4 \pm 2.6$ & $-3.3 \pm 2.9$ & $-0.01 \pm 0.02$ & -0.06 to 0.04 & 0.635 \\
\hline 6-mo & $2.5 \pm 2.4$ & $-3.2 \pm 3.1$ & $-0.03 \pm 0.02$ & -0.07 to 0.02 & 0.297 \\
\hline \multicolumn{6}{|l|}{ SF-12 PCS } \\
\hline Preop & $33.1 \pm 8.2$ & & & & \\
\hline 6-wk & $36.0 \pm 9.1$ & $2.2 \pm 8.2$ & $0.18 \pm 0.14$ & -0.11 to 0.48 & 0.217 \\
\hline $12-w k$ & $40.0 \pm 10.9$ & $5.6 \pm 9.9$ & $0.15 \pm 0.17$ & -0.19 to 0.50 & 0.368 \\
\hline 6-mo & $41.1 \pm 10.8$ & $8.1 \pm 10.5$ & $0.09 \pm 0.15$ & -0.20 to 0.39 & 0.538 \\
\hline
\end{tabular}

* $\mathrm{p}$ values were calculated using multivariate regression controlling for age, sex, smoking status, $\mathrm{BMI}$ category, $\mathrm{CCl}$, number of levels, and preoperative outcome value.

depressed patients having a lower return to work rate following lumbar fusion. ${ }^{36}$

The findings of the present study challenge the majority of previously published literature suggesting an association between preoperative psychological symptoms and postoperative outcomes following spinal surgery. . $^{1,3-7,26,30,32,34}$ While many of these studies evaluated outcomes of lumbar spine surgery, few have assessed cervical spine patients. In a study of 151 patients undergoing surgery for cervical radiculopathy, Skeppholm et al. reported that patients with high preoperative mental distress reported worse overall outcomes at 2 years following surgery. ${ }^{37}$ Likewise, Alvin et al. concluded that patients with greater preoperative depression had less improvement in quality of life following posterior cervical fusion. ${ }^{4}$ Two other studies assessed the effect of preoperative depression on postoperative patientreported pain and disability, reporting that patients with higher levels of depression experienced inferior outcomes following cervical disc replacement. ${ }^{20,41}$ However, none of these studies assessed patients undergoing ACDF.

While several studies do conclude that preoperative mental health is associated with postoperative outcomes following cervical spine surgery, such conclusions are not supported by our results. The relatively few studies published reporting no association may be due to publication bias, a well-reported occurrence in which positive results are more likely to be published than studies reporting negative results. ${ }^{11,13,14,28,29}$ This trend of preferentially publishing studies that demonstrate a significant effect may overrepresent the effect of mental health on PROs following cervical and lumbar spine surgery.
Interestingly, the preoperative MCS score was associated with preoperative perceived disability and arm pain, but it was not associated with patient-reported neck pain. These results imply that disability and arm pain may be more closely correlated to mental health than neck pain. However, causation cannot be inferred due to the retrospective nature of this study. It is unclear if worse mental health status leads to an increased reporting of disability, or if worse disability leads to worse mental health status. Consistent with the results demonstrated in the current study, depression has been associated with patient-reported disability in patients scheduled to undergo spine surgery. ${ }^{12,38}$

The present study is not without limitations. First, all procedures were performed by a single surgeon at a single academic center, limiting the generalizability to other patient populations and surgeons. Second, there are inherent biases present with all retrospective studies, and, as mentioned previously, causality cannot be determined.

TABLE 3. Percentage of patients who achieved MCID by MCS half

\begin{tabular}{lccc}
\hline \multirow{2}{*}{ Variable } & \multicolumn{2}{c}{ No. of Patients (\%) } & \\
\cline { 2 - 3 } & Bottom Half $(\mathrm{n}=26)$ & Top Half $(\mathrm{n}=26)$ & p Value* \\
\hline NDI & $11(42.3)$ & $14(53.9)$ & 0.788 \\
\hline VAS neck & $15(57.7)$ & $13(50.0)$ & 0.519 \\
\hline VAS arm & $10(38.5)$ & $10(38.5)$ & 1.00 \\
\hline SF-12 PCS & $15(57.7)$ & $17(65.4)$ & 0.489 \\
\hline
\end{tabular}

* $p$ values were calculated using multivariate regression controlling for age, sex, smoking status, BMl category, $\mathrm{CCl}$, and preoperative outcome value. 
TABLE 4. MCS score association with attainment of MCID in patient-reported outcome measures.

\begin{tabular}{lccc}
\hline \multicolumn{1}{c}{ Variable } & No. of Patients & Mean MCS \pm SD & p Value* \\
\hline NDI & & & 0.730 \\
\hline MCID not achieved & 27 & $49.0 \pm 11.8$ & \\
\hline MCID achieved & 25 & $43.8 \pm 13.9$ & \\
\hline VAS neck & & & 0.883 \\
\hline MCID not achieved & 24 & $45.7 \pm 13.1$ & \\
\hline MCID achieved & 28 & $47.2 \pm 13.1$ & \\
\hline VAS arm & & & 0.284 \\
\hline MCID not achieved & 32 & $46.3 \pm 11.8$ & \\
\hline MCID achieved & 20 & $46.9 \pm 15.0$ & \\
\hline SF-12 PCS & & & 0.503 \\
\hline$\quad$ MCID not achieved & 32 & $46.9 \pm 13.5$ & \\
\hline MCID achieved & 20 & $45.8 \pm 12.3$ & \\
\hline
\end{tabular}

* $p$ values were calculated using multivariate regression controlling for age, sex, smoking status, body mass index category, $\mathrm{CCl}$, insurance status, and preoperative outcome value.

Third, the total number of patients who completed all surveys was small, with a patient loss of $35.8 \%$ due to nonresponse. At $80 \%$ power and $\alpha=0.05$, a sample size of 56 would be sensitive enough to detect effect sizes (for mean differences) for all PROs included..$^{35}$ As such, our population of 52 patients may be slightly underpowered to detect an association between preoperative mental health status and changes in disability and pain. However, none of the results demonstrated trends toward significance, so this is unlikely. While longer follow-up would strengthen the results of the study, statistically significant improvements in neck VAS score, arm VAS score, NDI, SF-12 PCS score, and EQ-5D at 3 months postoperatively have been demonstrated in other instances. ${ }^{35}$ Fourth, the sensitivity and specificity of the mental health cutoff is limited by the use of only one survey. However, the SF-12 MCS has been demonstrated to be acceptable for detecting both active and recent depressive disorders in the general population. ${ }^{40}$ Finally, the evolution of mental health postoperatively for improvement could not be analyzed because of lack of survey response during follow-up. Previously, Vilagut et al. ${ }^{40}$ noted that the optimal SF-12 MCS score cutoff for detection of depressive disorders was 40.2-45.6. Thus, our cutoff value of 48 may represent an adequate point for detection of depressive disorders.

\section{Conclusions}

The present study suggests that preoperative mental health status (assessed using the SF-12 MCS) is not predictive of change in NDI, neck VAS, arm VAS, or SF-12 PCS score from preoperative to postoperative time points following ACDF. Although increased preoperative disability was associated with lower preoperative MCS score, patients with worse mental health status demonstrated similar improvements in PRO measures following ACDF. Future studies assessing alternative preoperative variables may discover alternative predictors of worse outcomes following cervical spine surgery.

\section{References}

1. Adogwa O, Parker SL, Shau DN, Mendenhall SK, Aaronson OS, Cheng JS, et al: Preoperative Zung Depression Scale predicts outcome after revision lumbar surgery for adjacent segment disease, recurrent stenosis, and pseudarthrosis. Spine J 12:179-185, 2012

2. Adogwa O, Parker SL, Shau DN, Mendenhall SK, Bydon A, Cheng JS, et al: Preoperative Zung depression scale predicts patient satisfaction independent of the extent of improvement after revision lumbar surgery. Spine J 13:501-506, 2013

3. Adogwa O, Verla T, Thompson P, Penumaka A, Kudyba K, Johnson K, et al: Affective disorders influence clinical outcomes after revision lumbar surgery in elderly patients with symptomatic adjacent-segment disease, recurrent stenosis, or pseudarthrosis: clinical article. J Neurosurg Spine 21:153159,2014

4. Alvin MD, Miller JA, Sundar S, Lockwood M, Lubelski D, Nowacki AS, et al: The impact of preoperative depression on quality of life outcomes after posterior cervical fusion. Spine J 15:79-85, 2015

5. Andersen T, Christensen FB, Bünger C: Evaluation of a Dallas Pain Questionnaire classification in relation to outcome in lumbar spinal fusion. Eur Spine J 15:1671-1685, 2006

6. Arpino L, Iavarone A, Parlato C, Moraci A: Prognostic role of depression after lumbar disc surgery. Neurol Sci 25:145147,2004

7. Block AR, Ohnmeiss DD, Guyer RD, Rashbaum RF, Hochschuler SH: The use of presurgical psychological screening to predict the outcome of spine surgery. Spine J 1:274-282, 2001

8. Brodsky AE, Khalil MA, Sassard WR, Newman BP: Repair of symptomatic pseudoarthrosis of anterior cervical fusion. Posterior versus anterior repair. Spine (Phila Pa 1976) 17:1137-1143, 1992

9. Cannada LK, Scherping SC, Yoo JU, Jones PK, Emery SE: Pseudoarthrosis of the cervical spine: a comparison of radiographic diagnostic measures. Spine (Phila Pa 1976) 28:46-51, 2003

10. Chaichana KL, Mukherjee D, Adogwa O, Cheng JS, McGirt MJ: Correlation of preoperative depression and somatic perception scales with postoperative disability and quality of life after lumbar discectomy. J Neurosurg Spine 14:261267, 2011

11. Chalmers I: Underreporting research is scientific misconduct. JAMA 263:1405-1408, 1990

12. Chapin L, Ward K, Ryken T: Preoperative depression, smoking, and employment status are significant factors in patient satisfaction after lumbar spine surgery. J Spinal Disord Tech [epub ahead of print], 2015

13. Dwan K, Altman DG, Arnaiz JA, Bloom J, Chan AW, Cronin E, et al: Systematic review of the empirical evidence of study publication bias and outcome reporting bias. PLoS One 3:e3081, 2008

14. Easterbrook PJ, Berlin JA, Gopalan R, Matthews DR: Publication bias in clinical research. Lancet 337:867-872, 1991

15. Elder BD, Sankey EW, Theodros D, Bydon M, Rory Goodwin C, Lo SF, et al: Successful anterior fusion following posterior cervical fusion for revision of anterior cervical discectomy and fusion pseudarthrosis. J Clin Neurosci 24:57-62, 2016

16. Elsamadicy AA, Adogwa O, Cheng J, Bagley C: Pretreatment of depression before cervical spine surgery improves patients' perception of postoperative health status: a retrospective, single institutional experience. World Neurosurg 87:214-219, 2016

17. Farivar SS, Cunningham WE, Hays RD: Correlated physical and mental health summary scores for the SF-36 and SF-12 Health Survey, V.I. Health Qual Life Outcomes 5:54, 2007 
18. Forero CG, Vilagut G, Adroher ND, Alonso J: Multidimensional item response theory models yielded good fit and reliable scores for the Short Form-12 questionnaire. J Clin Epidemiol 66:790-801, 2013

19. Gandek B, Ware JE, Aaronson NK, Apolone G, Bjorner JB, Brazier JE, et al: Cross-validation of item selection and scoring for the SF-12 Health Survey in nine countries: results from the IQOLA Project. International Quality of Life Assessment. J Clin Epidemiol 51:1171-1178, 1998

20. He J, Xiong W, Li F, Luo W, Gao S: Depression influences pain and function after cervical disc arthroplasty. J Neurosurg Sci [epub ahead of print], 2014

21. Herron LD, Turner J, Clancy S, Weiner P: The differential utility of the Minnesota Multiphasic Personality Inventory. A predictor of outcome in lumbar laminectomy for disc herniation versus spinal stenosis. Spine (Phila Pa 1976) 11:847850,1986

22. Kang SS, Lee JS, Shin JK, Lee JM, Youn BH: The association between psychiatric factors and the development of chronic dysphagia after anterior cervical spine surgery. Eur Spine J 23:1694-1698, 2014

23. Katz JN, Lipson SJ, Brick GW, Grobler LJ, Weinstein JN, Fossel AH, et al: Clinical correlates of patient satisfaction after laminectomy for degenerative lumbar spinal stenosis. Spine (Phila Pa 1976) 20:1155-1160, 1995

24. Katz JN, Stucki G, Lipson SJ, Fossel AH, Grobler LJ, Weinstein JN: Predictors of surgical outcome in degenerative lumbar spinal stenosis. Spine (Phila Pa 1976) 24:2229-2233, 1999

25. Kjellby-Wendt G, Styf JR, Carlsson SG: The predictive value of psychometric analysis in patients treated by extirpation of lumbar intervertebral disc herniation. J Spinal Disord 12:375-379, 1999

26. LaCaille RA, DeBerard MS, Masters KS, Colledge AL, Bacon W: Presurgical biopsychosocial factors predict multidimensional patient: outcomes of interbody cage lumbar fusion. Spine J 5:71-78, 2005

27. Li S, Qi M, Yuan W, Chen H: The impact of the depression and anxiety on prognosis of cervical total disc replacement. Spine (Phila Pa 1976) 40:E266-E271, 2015

28. Liebeskind DS, Kidwell CS, Sayre JW, Saver JL: Evidence of publication bias in reporting acute stroke clinical trials. Neurology 67:973-979, 2006

29. Littner Y, Mimouni FB, Dollberg S, Mandel D: Negative results and impact factor: a lesson from neonatology. Arch Pediatr Adolesc Med 159:1036-1037, 2005

30. McKillop AB, Carroll LJ, Battié MC: Depression as a prognostic factor of lumbar spinal stenosis: a systematic review. Spine J 14:837-846, 2014

31. Menendez ME, Neuhaus V, Bot AG, Ring D, Cha TD: Psychiatric disorders and major spine surgery: epidemiology and perioperative outcomes. Spine (Phila Pa 1976) 39:E111E122, 2014

32. Miller JA, Derakhshan A, Lubelski D, Alvin MD, McGirt MJ, Benzel EC, et al: The impact of preoperative depression on quality of life outcomes after lumbar surgery. Spine $\mathbf{J}$ 15:58-64, 2015

33. Ng LC, Tafazal S, Sell P: The effect of duration of symptoms on standard outcome measures in the surgical treatment of spinal stenosis. Eur Spine J 16:199-206, 2007

34. Pakarinen M, Vanhanen S, Sinikallio S, Aalto T, Lehto SM, Airaksinen O, et al: Depressive burden is associated with a poorer surgical outcome among lumbar spinal stenosis patients: a 5-year follow-up study. Spine J 14:2392-2396, 2014
35. Parker SL, Godil SS, Shau DN, Mendenhall SK, McGirt MJ: Assessment of the minimum clinically important difference in pain, disability, and quality of life after anterior cervical discectomy and fusion: clinical article. J Neurosurg Spine 18:154-160, 2013

36. Parker SL, Godil SS, Zuckerman SL, Mendenhall SK, Devin CJ, McGirt MJ: Extent of preoperative depression is associated with return to work after lumbar fusion for spondylolisthesis. World Neurosurg 83:608-613, 2015

37. Skeppholm M, Fransson R, Hammar M, Olerud C: The association between preoperative mental distress and patient reported outcome measures in patients treated surgically for cervical radiculopathy. Spine J [epub ahead of print], 2016

38. Sundseth J, Kolstad F, Johnsen LG, Pripp AH, Nygaard OP, Andresen H, et al: The Neck Disability Index (NDI) and its correlation with quality of life and mental health measures among patients with single-level cervical disc disease scheduled for surgery. Acta Neurochir (Wien) 157:1807-1812, 2015

39. Trief PM, Ploutz-Snyder R, Fredrickson BE: Emotional health predicts pain and function after fusion: a prospective multicenter study. Spine (Phila Pa 1976) 31:823-830, 2006

40. Vilagut G, Forero CG, Pinto-Meza A, Haro JM, de Graaf R, Bruffaerts R, et al: The mental component of the Short-Form 12 Health Survey (SF-12) as a measure of depressive disorders in the general population: results with three alternative scoring methods. Value Health 16:564-573, 2013

41. Zong Y, Xue Y, Zhao Y, Ding H, He D, Li Z, et al: Depression contributed an unsatisfactory surgery outcome among the posterior decompression of the cervical spondylotic myelopathy patients: a prospective clinical study. Neurol Sci 35:1373-1379, 2014

\section{Disclosures}

The authors disclose the following. Dr. Bohl: support of nonstudy-related clinical or research effort from Cervical Spine Research Society. Dr. Singh: Consultant for DePuy, Zimmer, and Stryker; royalties from Zimmer, Stryker, Lippincott Williams \& Wilkins, Thieme, Jaypee Publishing, and Slack publishing; clinical or research support for this study from a CSRS resident grant; direct stock ownership in Avaz Surgical LLC and Vital 5 LLC; and board of directors for CSRS, ISASS, AAOS, SRS, and Vertebral Column-ISASS.

\section{Author Contributions}

Conception and design: Singh, Mayo, Massel, Bohl, Basques, Yacob. Acquisition of data: Singh, Mayo, Massel, Narain, Long, Modi. Analysis and interpretation of data: Singh, Mayo, Massel, Bohl, Narain, Hijji, Basques, Yacob. Drafting the article: Singh, Mayo, Massel, Narain, Hijji, Long, Modi, Basques. Critically revising the article: all authors. Reviewed submitted version of manuscript: all authors. Approved the final version of the manuscript on behalf of all authors: Singh. Statistical analysis: Singh, Mayo, Massel, Bohl, Narain, Basques. Administrative/technical/ material support: Singh, Narain, Hijji. Study supervision: Singh.

\section{Correspondence}

Kern Singh, Department of Orthopaedic Surgery, Rush University Medical Center, 1611 W Harrison St., Ste. 300, Chicago, IL 60612. email: kern.singh@rushortho.com. 